\title{
Dengue and brain hemorrhage
}

\section{Hemorragia cerebral e dengue}

Dear editor,

The recent report on "Dengue and brain hemorrhage" is very interesting ${ }^{1}$. Daher et al. reported an interesting case of diffuse brain hemorrhage in a dengue patient ${ }^{1}$. In fact, the brain hemorrhage in dengue is an interesting neurological complication of dengue. An interesting namely expanded dengue syndrome should be discussed. This condition is an extremely severe dengue presentation, it has the component of brain hemorrhage and other unusual complications such as subacute thyroiditis ${ }^{2}$.
The challenge in management of intracranial hemorrhage due to dengue is the profound thrombocytopenia. The resolution of bleeding can be spontaneous in some cases ${ }^{2}$. However, in the case with vital site bleeding, the consideration of surgical management is needed. If there is no proper management, the fatal outcome is common ${ }^{3}$. For those cases, the use of platelet transfusion can be useful and the surgical managements usually provide good outcome $\mathrm{e}^{4}$.

Beuy Joob ${ }^{1}$, Viroj Wiwanitkit ${ }^{2}$

\section{References}

1. Daher RT, Marussi VH, Pedroso JL, Oliveira AS, Amaral LL. Dengue virus infection presenting with diffuse brain hemorrhage. Arq Neuropsiquiatr. 2014;72(10):815. http://dx.doi.org/10.1590/0004-282X20140131

2. Assir MZ, Jawa A, Ahmed HI. Expanded dengue syndrome: subacute thyroiditis and intracerebral hemorrhage. BMC Infect Dis. 2012;12:240. http://dx.doi.org/10.1186/1471-2334-12-240
3. Wiwanitkit V. Magnitude and pattern of neurological pathology in fatal dengue hemorrhagic fever: a summary of Thai cases. Neuropathology. 2005;25(4):398. http://dx.doi.org/10.1111/j.1440-1789.2005.00653.x

4. Kumar R, Prakash O, Sharma BS. Intracranial hemorrhage in dengue fever: management and outcome: a series of 5 cases and review of literature. Surg Neurol. 2009;72(4):429-33. http://dx.doi.org/10.1016/j.surneu.2009.01.021 